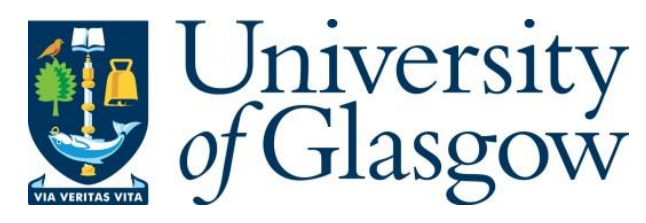

Xiao, Z., Liu, X., Harper, L. T., Endruweit, A. and Warrior, N. A. (2020) Modelling the permeability of random discontinuous carbon fibre preforms. Journal of Composite Materials, (doi: $\underline{10.1177 / 0021998320902506)}$

There may be differences between this version and the published version. You are advised to consult the publisher's version if you wish to cite from it.

http://eprints.gla.ac.uk/209329/

Deposited on: 11 February 2020

Enlighten - Research publications by members of the University of Glasgow http://eprints.gla.ac.uk 


\title{
Modelling the permeability of random discontinuous carbon fibre preforms
}

\author{
Z. Xiao ${ }^{1}$, X. Liu $^{2}$, L.T. Harper ${ }^{3}$, A. Endruweit ${ }^{3}$, N.A. Warrior ${ }^{3}$ \\ ${ }^{1}$ School of Engineering, University of Glasgow, UK, G12 8QQ \\ ${ }^{2}$ Advanced Composite Centre, University of Nottingham, Ningbo 315100, China \\ ${ }^{3}$ Composites Research Group, Faculty of Engineering, University of Nottingham, UK, NG7 2RD
}

\section{Abstract}

A force-directed algorithm was developed to create representative geometrical models of fibre distributions in Directed Carbon Fibre Preforms (DCFP). Local permeability values were calculated for the preform models depending on the local fibre orientation, distribution and volume fraction. The effect of binder content was incorporated by adjusting the principal permeability values of the meso-scale discontinuous fibre bundles, using corresponding experimental data obtained for unidirectional non-crimp fabrics. The model provides an upper boundary for the permeability of DCFP architectures, where predictions are within one standard deviation of the experimental mean for all architectures studied.

\section{Key words}

Permeability; Discontinuous carbon fibre; Computational modelling 


\section{Introduction}

Directed Carbon Fibre Preforming (DCFP) is an automated process for producing non-woven reinforcements for composites from chopped fibre tows [1]. A robot-mounted chopper head cuts continuous fibre tows into segments of defined length and sprays the segments together with a polymer powder binder ( $\sim 5 \mathrm{wt} \%)$ onto a perforated tool, following a pre-defined deposition path. Air is evacuated from underneath the tool, so that the resulting pressure differential holds the deposited fibres in place. A second (matched) perforated tool is lowered to compress the preform to control its thickness before hot air is cycled through the perforations to activate the binder. The binder-stabilised preform is extracted from the preforming station and transferred to a separate moulding station for injection of liquid resin. DCFP has been adopted successfully in the automotive industry as an alternative to sheet moulding compounds for semi-structural composite components [2, 3]. In general, the final reinforcement fibre architecture is more controllable in components produced by Resin Transfer Moulding (RTM) than in components made by compression moulding, as unwanted flow-induced fibre alignment or fibre curvature can be largely avoided. The DCFP process can produce net-shaped preforms and is suitable for medium production volumes $(>30,000$ parts per annum) [4]. However, compared with frequently used woven, stitch-bonded or braided reinforcement fabrics with equivalent areal mass, the permeability of non-woven DCFP materials is typically an order of magnitude lower and has higher levels of local variability [5]. This results in longer times for reinforcement impregnation and causes uncertainty during the resin injection process.

In general, the permeability of dual-scale reinforcements, such as fabrics, where continuous fibre bundles are arranged in a defined pattern, or DCFP materials, where discontinuous fibre bundles are arranged randomly, is governed by flow in the fibre bundles and between the 
bundles. This dual-scale permeability has been studied numerically and experimentally for saturated and unsaturated flow in liquid moulding processes [6-9]. To account for the difference in flow velocities in bundles and between bundles, which typically results in delayed impregnation of the fibre bundles in unsaturated flow, it has been proposed to model fibre bundles as a fluid sink in a porous medium with uniform permeability [8,9]. Furthermore, unsaturated flow is affected by capillary pressure which is sometimes considered in modelling of flow and void formation within fibre bundles [8, 10-12]. However, the effect of capillary pressure on fluid flow tends to be negligible if the injection pressure is high enough [13]. Importantly, both material scales affect the impregnation of DCFP materials and need to be considered in permeability modelling.

When High-Pressure RTM (70 bar to 150 bar injection pressure) [14] is used to inject fastcuring epoxy resins [15-17] to obtain short cycle times, large in-mould forces can cause fibre washing or preform tearing, as fixation through clamping of preform edges (areas of high fibre volume fraction outside the final trim line) is ineffective with discontinuous fibres. Consequently, higher binder content ( $10 \mathrm{wt} \%)$ is required for preform stabilisation to prevent fibre movement during injection, which may reduce the preform permeability and can have an adverse effect on the mechanical properties of the moulded component. Rohatgi and Lee [18] found that the permeability of woven preforms decreased by $\sim 40 \%$ when binder content increased from $0 \mathrm{wt} \%$ to $8 \mathrm{wt} \%$. Powder binder tends to remain on the surface of the fibre bundles, blocking meso-scale flow channels between bundles and hence reducing permeability. Furthermore, soluble binders mix with the resin and can increase its viscosity, reducing the velocity of flow through the porous preform [19].

In a previous study, the variability in permeability measured for a series of DCFP preforms with identical specifications was found to be as high as $34 \%$ [5], which can cause great 
uncertainty in terms of developing flow patterns, affecting tooling design and injection strategy. This variability is related to local variations in meso-scale fibre architecture, which depends on four main factors, i.e. the uniformity of the superficial density, the fibre orientation distribution, the fibre length distribution, and the average tow filament count. Permeability variations need to be controlled in order to make the resin injection process more robust. A previously developed stochastic model to predict the local permeability for DCFP preforms was based on a simple $2 \mathrm{D}$ random sequential adsorption model $[5,20]$. This model used beam elements to represent only the axes of discontinuous carbon fibre bundles, which introduced errors in terms of fibre distribution. Additionally, the through-thickness fibre distribution was simplified by assuming three idealised cases (homogenised, clustered, uniform) [5]. Local permeability fields were generated, which were used as input for resin flow simulations. Irregular flow fronts were observed in the simulations, reflecting the effect of meso-scale material variability. Global permeability values derived from the simulations were between $25 \%$ and $108 \%$ higher than corresponding experimental values, depending on the assumed through-thickness distribution of the bundles. This difference was attributed to the approach for generating local permeabilities, which overlooked the non-uniformity of through-thickness fibre distributions and the effect of applied binder on effective flow channel dimensions.

This paper presents a novel approach for local permeability calculation, using an alternative geometrical modelling scheme to produce more representative discontinuous fibre architectures. A force-directed algorithm is adopted to simulate the through-thickness consolidation of the deposited fibre bundles during preforming, in order to achieve realistic local fibre distributions [21]. The effect of preform binder content is taken into account in the calculation of local permeability values, which are used as input for resin injection simulations. 
The model is applied to DCFP preforms with different fibre volume fractions, and results are validated by experimental testing.

\section{Materials}

For the experimental study, DCFP preforms were manufactured by the process outlined by Harper et al. [1]. Toray T700-50C 12K carbon fibre was used, which had an average bundle width of $4.6 \mathrm{~mm}$. A reactive epoxy binder (Momentive EPS620) was used for preform stabilisation, which was cured under vacuum at $120^{\circ} \mathrm{C}$ for 10 minutes. Details of all preforms manufactured are listed in Table 1.

For additional permeability tests, a unidirectional (UD) carbon fibre non-crimp fabric (NCF) with an areal mass of $375 \mathrm{~g} / \mathrm{m}^{2}$ was used (FCIM356, supplied by Hexcel Leicester). This was made from 12K carbon fibre bundles (Toray T620-50C), with a stitch thread from polyester. Permeability measurements were performed using engine oil with measured viscositytemperature characteristics $\left(\eta=0.103 \mathrm{~Pa} \cdot \mathrm{s}\right.$ at $\left.20^{\circ} \mathrm{C}\right)$ as a test fluid.

\section{Experimental permeability study}

\subsection{Experimental method}

Due to the local variability in the architecture and permeability of DCFP preforms, flow front shapes observed in radial flow experiments deviate from ellipses [22, 23], which creates difficulties in calculating representative global permeability values. Here, linear (unidirectional) flow experiments were conducted where an approximate permeability value can still be determined, even if the flow front shape is irregular as a result of local material variations. The preform is placed in a rectangular mould and fluid is injected at constant pressure through a linear gallery at one end. The pressure drop between injection gallery and 
flow front, $\Delta P$, and the time, $t$, for the flow front to reach a given position, $x$, are measured. This allows the permeability, $K$, to be calculated using

$$
K=\frac{x^{2} \eta \varepsilon}{2 \Delta P t}
$$

which is derived from integration of Darcy's law in one dimension. Here, $\eta$ is the fluid viscosity,

$$
\varepsilon=1-V_{f}
$$

the porosity and $V_{f}$ the fibre volume fraction. This method is accurate if the linear flow front is straight and still allows an approximation for the permeability to be derived if the flow front is not straight due to local variations in the material.

For the tests, coupons with dimensions $280 \mathrm{~mm} \times 115.5 \mathrm{~mm}$ were stamped from each preform using a die cutter to produce neat square edges. Each coupon was $0.5 \mathrm{~mm}$ wider than the tool cavity used for the flow experiments to obtain a tight fit and prevent race tracking. Figure 1 shows a schematic of the rectangular mould tool used to perform the unidirectional permeability measurements. The cavity height of the mould was $2 \mathrm{~mm}$ when assembled. More detail on the experimental method is provided in a previous publication [5]. The test fluid was injected into the mould at a constant pressure of 1.5 bar. Readings of a pressure sensor (indicated in Figure 1) were used to detect the arrival of the flow front at a position $250 \mathrm{~mm}$ from the inlet. The time for the flow front to reach this position was typically in the order of 30 seconds for a DCFP preform with a fibre volume fraction of $31 \%$. An estimate for the permeability was calculated using Eqs. (1) and (2).

\subsection{Experimental results}

The in-plane permeability was measured for up to 30 coupons for each type of DCFP material, which were taken from three separate preforms. For DCFP samples at a binder content of 10 $w t \%$, the level of variability was quantified, and the size of the population required to achieve 
a representative mean value was determined. The cumulative average permeability value is plotted as a function of the number of measurements in Figure 2. For the lower fibre volume fraction of $31 \%, 10$ measurements are required before the average permeability value reaches a plateau. The average permeability value after 10 iterations is within $98 \%$ of the mean value after 30 iterations, which is an acceptable error, given the local variability of the material. A typical flow front for a DCFP preform with a fibre volume fraction of $31 \%$ is shown in Figure 3, which was taken in-situ during a permeability measurement. The observed irregularity is caused by the non-uniform distribution of fibre bundles. As there are only 4.2 tows $/ \mathrm{cm}^{2}$ on average for this particular fibre architecture, local variability results in large resin rich regions. The uniformity improves for specimens with a $46 \%$ fibre volume fraction, i.e. 6.3 tows $/ \mathrm{cm}^{2}$ on average. Consequently, the representative average permeability value is achieved after just 4 iterations, as shown in Figure 2. The coefficient of variation (standard deviation / average) of the permeability at $V_{f}=0.31 \%$ after 10 iterations and at $V_{f}=0.46$ after 4 iterations is in the order of $25 \%$. Based on the results presented in Figure 2, 15 measurements were performed for all other preform types, as indicated in Table 1.

\subsection{Additional permeability tests}

The effect of binder needs to be taken into consideration in order to accurately predict the permeability for DCFP preforms. Since the effect of different binder content levels on permeability would be indistinguishable from the effect of inherent material variability for DCFP preforms, a series of permeability tests were conducted for a UD NCF to enable the effect to be identified clearly. NCF was selected, as tests on UD tows are difficult to perform at low binder content, as the fibres are susceptible to moving during resin injection, particularly for low fibre volume fractions where preform clamping is limited within the tool 
cavity. Here, the presence of the stitch yarn will influence the absolute permeability values, but this is considered acceptable, as the purpose of this study is to provide a relative measure for the influence of increasing binder content.

The powder binder was deposited evenly on one surface of each of the four UD NCF layers in a specimen and cured under vacuum at $120^{\circ} \mathrm{C}$, similar to the DCFP preforms. The fibre volume fraction of the UD NCF specimens during the permeability tests was $46 \%$. Tests were conducted both parallel and transverse to the fibre direction, employing the experimental method described above. The resulting permeability values were used to calculate knockdown factors in an analytical expression to determine the input values for the DCFP permeability model.

Figure 4 shows the measured permeability values, $k_{1}$ and $k_{2}$, for UD NCF specimens at three different EPS620 binder levels: 0 wt\%, 5 wt\%, and 10 wt\%. The value of $k_{1}$ (orientated along the fibre direction) decreased by $60.1 \%$ (from $4.04 \times 10^{-10} \mathrm{~m}^{2}$ to $1.61 \times 10^{-10} \mathrm{~m}^{2}$ ) when 5 wt\% of binder was added to the preform. However, when the binder level increased from $5 \mathrm{wt} \%$ to $10 \mathrm{wt} \%$, the effect of additional binder became less significant, as the permeability only decreased by a further $4 \%$ (from $1.61 \times 10^{-10} \mathrm{~m}^{2}$ to $1.55 \times 10^{-10} \mathrm{~m}^{2}$ ). Compared to $k_{1}$, the permeability transverse to the fibre direction, $k_{2}$, is less sensitive to an increase in the binder level, particularly in the range of $0 \mathrm{wt} \%$ to $5 \mathrm{wt} \%$, as shown Figure 4 . The permeability values at different binder levels are listed in Table 2. Figure 5 (a) shows that the flow progresses quickly through the gaps between the fibre tows in the $k_{1}$ direction. In the $k_{2}$ direction (Figure 5 (c)), the flow velocity is high along the stitches, which compress the fibre tows locally and form flow channels, when there is no binder in the preforms. Dry spots were entrapped behind the flow front as observed in Figure 5 (c), as the flow velocity is much smaller in the fibre tows than in the gaps formed around the stitches. When the binder level was increased 
to $10 \mathrm{wt} \%$, the spacing between tows still provided flow channels (Figure $5(b)$ ) in the $k_{1}$ direction, albeit at reduced effective dimensions. The propagation of the flow front in the $k_{2}$ direction (Figure $5(\mathrm{~d})$ ) was affected by the binder which reduces the flow channel dimensions around the stitches, resulting in a more linear profile, although the effect on the value of $k_{2}$ is less significant. These results show that the binder influences the principal permeabilities, $k_{1}$ and $k_{2}$, in different ways.

\section{$4 \quad$ DCFP permeability modelling}

\subsection{Modelling approach}

The permeability of a preform is governed by intra-bundle flow and inter-bundle flow. Both can be included in analytical models to predict the local permeability of the preform. Gebart [24] proposed two equations to describe the permeability of aligned fibre bundles along the fibre axis,

$$
k_{1}=\frac{R_{f}^{2}}{4 c_{1}} \frac{\left(1-V_{f}\right)^{3}}{V_{f}^{2}}
$$

and perpendicular to the fibre axis,

$$
k_{2}=c_{2}\left(\sqrt{\frac{V_{f m a x}}{V_{f}}}-1\right)^{\frac{5}{2}} R_{f}^{2} .
$$

Here, $R_{f}$ is the fibre radius, $V_{f}$ the fibre volume fraction, and $c_{1}, c_{2}$, and $V_{\text {fmax }}$ are geometrical constants which depend on the fibre packing arrangement. The equivalent permeability of a gap between two fibre bundles is estimated as

$$
K=\frac{H^{2}}{12}
$$

where $H$ is the height of the gap [25]. 
The in-plane permeability of a randomly orientated fibre bundle, $i$, within a DCFP architecture where the local orientation is described by an angle, $\alpha_{i}$, can be expressed as

$$
K_{i}\left(\Delta \alpha_{i}\right)=\left(\begin{array}{ll}
k_{1} \cos ^{2} \Delta \alpha_{i}+k_{2} \sin ^{2} \Delta \alpha_{i} & \left(k_{2}-k_{1}\right) \sin \Delta \alpha_{i} \cos \Delta \alpha_{i} \\
\left(k_{2}-k_{1}\right) \sin \Delta \alpha_{i} \cos \Delta \alpha_{i} & k_{1} \sin ^{2} \Delta \alpha_{i}+k_{2} \cos ^{2} \Delta \alpha_{i}
\end{array}\right) .
$$

Here, $\Delta \alpha_{i}$ is equal to $\left(\alpha_{i}-\alpha_{0}\right)$, and $\alpha_{0}$ is the local principal material axis of the preform. Modelling a DCFP preform as a stack of $N$ identical fibre bundles and $M$ through-thickness gaps between bundles, the local permeability can be estimated as

$$
K=\sum_{i=1}^{N} \frac{T_{f}}{T_{m}} K_{i}\left(\Delta \alpha_{i}\right)+\sum_{j=1}^{M} \frac{h_{j}}{T_{m}} \frac{h_{j}{ }^{2}}{12}
$$

where $T_{f}$ is the thickness of the $N$ fibre bundles, $T_{m}$ is the inner mould cavity thickness, and values of $h_{j}$ are the heights of the $M$ gaps between fibre bundles [5]. Out of the three previously discussed cases of through-thickness fibre distribution (homogenised, clustered, uniform), uniformly spaced fibre bundles produce the most accurate permeability predictions. However, these values are still $25 \%$ higher than experimental data. In practice, the fibre bundles are not evenly distributed through the thickness, therefore previous simulation results [20] represent an over-estimation of the DCFP permeability.

\subsection{Implementation}

In the current work, four steps were implemented to create geometrical models and predict the permeability of DCFP preforms: 1) A force-directed algorithm was used to simulate deposition of discontinuous fibre bundles to create a representative model of the DCFP architecture; 2) The fibre arrangement was analysed using a Matlab script to determine the local fibre volume fraction, local fibre orientations and through-thickness spacing; 3 ) Local permeability values were calculated; 4) a commercial software package (PAM-RTM) was used to simulate resin flow through a preform with non-uniform permeability distribution values 
in order to calculate global permeability values based on the predicted fill time for a given flow length. The schematics of these four steps is presented in Figure 6.

\subsubsection{Tow deposition simulation}

The 3D geometry representation of a DCFP preform was produced by an algorithm developed by Harper et al. [21]. A typical output from the model is shown in Figure 7. The fibre bundle properties (tow size, fibre length, tow volume fraction), model dimensions and global fibre volume fraction were defined according to Table 3.

Each bundle was deposited sequentially within the model, and a cropping algorithm was employed to trim the bundle if it crossed the boundary of the domain. Fibre bundles were continuously deposited over the region of interest until the target fibre volume fraction was achieved. A force-directed approach using an attraction-repulsion mechanism was used to prevent bundle intersections and to define the through-thickness distribution of fibre bundles [21]. When the fibre architecture generation is complete, each deposited fibre bundle is represented by a separate surface mesh.

\subsubsection{Fibre geometry analysis}

An algorithm was developed to assign the local number of fibre bundles, their orientation and through-thickness spacing, which are derived from the tow deposition model, to triangular finite elements (FE) in a 2D mesh representing the domain for the resin flow simulations. As it would be too expensive computationally to use the same mesh density for flow simulation as for modelling of the fibre bundle geometry, the triangular FE mesh was typically much coarser than the surface mesh representing each tow. Due to the lack of congruence between the two meshes, a rule needed to be defined for mapping of local fibre bundle properties to 
triangular finite elements which ensures that the global fibre volume fraction was approximately maintained. Here, a threshold area coverage was introduced to determine if the bundle properties were assigned to a partially overlapping triangular finite element. This means that the properties of a specific fibre bundle were considered in determining the properties of a specific finite element if the bundle surface mesh covered more than a specified threshold fraction of the area of the triangular element.

A sensitivity study was performed to determine an optimum area threshold to ensure the local fibre volume fraction was not misrepresented. Three carbon fibre tow sizes (T700 with filament diameter of $8 \mu \mathrm{m}$ ) were selected for investigation: $24 \mathrm{~K}, 12 \mathrm{~K}$, and $6 \mathrm{~K}$. The mesh information for all fibre architectures generated in this work is listed in Table 3. The width for each tow size was measured using a Vernier calliper.

The heights of through-thickness gaps between all fibre bundles were estimated within each triangular element. The vertical position of a tow was represented by the average vertical coordinates of tow surface elements within a triangular finite element, taking into consideration the thickness of the tow. If the vertical spacing between tows was less than or equal to the tow thickness, the spacing was set to 0 . If the sum of the tow thicknesses in any element was greater than $2 \mathrm{~mm}$ (the cavity height), all vertical inter-tow spacings were set to 0 , assuming all fibres were touching and the filaments from all tows were distributed uniformly [5].

The output from this analysis included the $x-y$ nodal coordinates of the finite elements, the number of tows within each element, the orientation of these tows and the vertical position of each tow relative to the base of the mould. This data was used to calculate local permeability values for each element using Eq. (7). 


\subsubsection{Local permeability calculation}

The approach proposed by Endruweit et al. [20] for approximating the local DCFP permeability was modified to account for the non-uniformity of the through-thickness interfibre spacing. The parameters used for calculation of more realistic local permeability values are listed in Table 4. Fibre density and diameter data were taken from the data sheet for T700 carbon fibre [26], while $c_{1}, c_{2}$ and $V_{\text {fmax }}$ were determined assuming quadratic fibre packing [5, 20].

The effect of powder binder was taken into account by applying percentage reductions (listed in Table 2) to the analytical values for $k_{1}$ and $k_{2}$ according to the permeability measurements for the UD NCF with different binder contents (Section 'Additional permeability tests').

\subsubsection{Flow simulation}

The domain sizes for FE simulations using PAM-RTM are listed in Table 3. One example (280 $\mathrm{mm} \times 110 \mathrm{~mm}$ ) is shown in Figure 8 . The cavity height, $H$, was $2 \mathrm{~mm}$. The short edges of the rectangular cavity are the resin inlet and outlet, respectively, whilst the long edges represent impermeable mould walls. The five points at a distance of $250 \mathrm{~mm}$ from the inlet (left edge) indicate a set of virtual pressure sensors. A constant injection pressure of 1.5 bar is set on the inlet, while the pressure at the outlet is 0 bar to create a pressure differential, $\Delta P$. The viscosity of the resin, $\eta$, is set to $0.103 \mathrm{~Pa} \cdot \mathrm{s}$. The time for the resin (indicated in red in Figure 8) to reach the five virtual pressure sensors is recorded. The average value is calculated, which is used in Eq. (1) to determine the global permeability. It is to be noted that, as each permeability test gives only a single value, 5 times as many tests need to be run (and averaged) to obtain the same accuracy as with the simulations. 


\section{Discussion}

\subsection{Geometrical model}

To obtain accurate representations of the DCFP architecture, it is important to ensure that the global fibre volume fraction is preserved when the 3D tow surface mesh is reduced to the 2D FE mesh (Section 'Fibre geometry analysis'). Global fibre volume fractions for different area threshold values are presented in Figure 9 for different DCFP architectures. The target global $V_{f}$ was set to $31 \%$, as indicated by the red horizontal line. The global fibre volume fraction is over-predicted by approximately $40 \%$ when no area threshold is used $\left(V_{f}\right.$ is predicted to be $44 \%$ rather than $31 \%)$. The magnitude of the error is a function of the fibre length. Larger errors occur for shorter fibres $(30 \mathrm{~mm})$, as more tow segments are present per unit volume compared with longer fibres.

As the area threshold value increases, the error is reduced, and the global fibre volume fraction approaches the target value. Figure 9 indicates that an area threshold of $70 \%$ is required to achieve a representative fibre volume fraction for all three fibre lengths investigated ( $30 \mathrm{~mm}, 50 \mathrm{~mm}$, and $100 \mathrm{~mm})$.

In order to validate this, the volume fraction for a range of fibre architectures listed in Table 3 was calculated. The calculated error for the majority of the architectures in Table 3 is less than $5 \%$ if the area threshold value is set to $70 \%$. The error values for fibre Architectures 1 to 3 indicate that the area threshold value appears to be independent of the global volume fraction. The $70 \%$ threshold value is effective when the ratio of the triangular element size to the seed size of the tow surface mesh is between 1.5 and 3.2, as the error for the calculated volume fraction is less than $5 \%$. The error for Architecture 14 is $50 \%$, as the seed size of the tow surface mesh $(1.13 \mathrm{~mm})$ is too large relative to the width of the $6 \mathrm{~K}$ tow $(2.4 \mathrm{~mm})$. Consequently, only two or three nodes are located across the fibre width, which leads to a 
poor mesh quality. When a finer tow seed size $(0.29 \mathrm{~mm})$ and triangular mesh size $(0.6 \mathrm{~mm})$ are used for the $6 \mathrm{~K}$ fibre architecture (Architecture 13), the error is within a more acceptable range $(\leq 5 \%)$.

Architecture 10 is similar, with a reported difference of $17 \%$ between the simulated fibre volume fraction and the target value. This is also due to the large triangular element size (5 $\mathrm{mm}$ ) in comparison to the width of the $24 \mathrm{~K}$ tow $(9.4 \mathrm{~mm})$. The error is reduced to $3.6 \%$ when the triangular element size is reduced by $50 \%$ to $2.5 \mathrm{~mm}$ (Architecture 8 ), which indicates the importance of selecting the correct seed size for the tow surface mesh and the triangular finite element size for these architectures. Whilst smaller finite elements improve computational accuracy, they result in an increase in computation time. Data listed in Table 5 indicates that the CPU time increases by a factor of approximately 10 (from $28 \mathrm{~s}$ to $267 \mathrm{~s}$ ) when the element size is reduced from $2.5 \mathrm{~mm}$ to $1.2 \mathrm{~mm}$.

The relationship between the seed size for the tow surface mesh, $S_{s}$, the triangular finite element size, $S_{g}$, and the width of tow, $W$, can be expressed as

$$
\left(D_{1} \times S_{S}\right) \leq S_{g} \leq \frac{w}{D_{2}},
$$

where $D_{1}$ and $D_{2}$ are design constants. The recommended values for $D_{1}$ and $D_{2}$ are 2.2 and 3.8 respectively, based on the results above, considering accuracy and computing time.

To show the effect of local fibre bundle arrangement on the global permeability value, an example 3D DCFP model was generated as described in Section 'Tow deposition simulation'. Based on the local fibre distribution, which is plotted in Figure 10 (a) where darker grey-scales indicate higher local fibre content, local permeabilities were calculated (Section 'Local permeability calculation') and subsequently imported into PAM-RTM. The effective global permeability was calculated from the resin flow simulation results, using the methodology outlined in Section 'Flow simulation'. Figure 10 shows that the flow front is irregular and that 
it correlates clearly with the local fibre distribution within the preform. Flow is hindered by the high fibre content regions, causing resin to flow faster through the low $V_{f}$ regions (as observed experimentally in Figure 3).

\subsection{Global permeability prediction}

The validity of flow simulations using PAM-RTM is checked by comparing results with experimentally determined permeability data. Figure 11 shows the simulation results of the cumulative average global permeability values for a DCFP architecture with a filament count of $12 \mathrm{~K}$, a fibre length of $45 \mathrm{~mm}$, and a binder content of $5 \mathrm{wt} \%$ at $V_{f}=31 \%$. For each iteration, a new randomised DCFP model was created using the same material parameters. As each simulation implies averaging of five times for the uneven flow front to reach a given distance from the injection gate, the simulation results converged after 3 iterations, and all values were in a narrow range $\left(15 \times 10^{-10} \mathrm{~m}^{2}\right.$ to $\left.16 \times 10^{-10} \mathrm{~m}^{2}\right)$. Convergence is significantly quicker than for the permeability tests, where only one value was determined in each experiment. The fibre volume fraction for models used in the flow simulations can be controlled with high accuracy, such that each individual DCFP model $(280 \mathrm{~mm} \times 110 \mathrm{~mm}$ ) has a fibre volume fraction of $31 \%$. Whereas the fibre volume fraction for specimens used for permeability tests cannot be controlled with the same accuracy. Experimental specimens are stamped from a larger preform, therefore local non-unifomity of the fibre volume fraction results in some variability in $V_{f}$ (between $30 \%$ and $32 \%$ ) of the test specimens, even if the global fibre volume fraction for the entire preform is accurate. This additional uncertainty can have a significant effect on the global permeability of the test specimens.

Table 6 compares permeability values for the DCFP structures at two levels of $V_{f}(31 \%$ and $46 \%)$, which were predicted using two different modelling methods and determined 
experimentally. Here, the 2D model refers to a previous approach which assumed that fibre bundles are evenly distributed through the preform thickness [20], while the 3D model refers to the approach discussed above, with random spacing between fibre bundles in the throughthickness direction. The results indicate that, in general, the permeability reduces as the binder content increases, since the binder material hinders fluid flow at the bundle-bundle contact points. As the fibre volume fraction increases, the effect of the binder content on the in-plane permeability becomes less significant. The permeability reduces by approximately $16 \%$ as the binder content is increased from $5 \mathrm{wt} \%$ to $10 \mathrm{wt} \%$ at $V_{f}=46 \%$, compared to a reduction of $27 \%$ at $V_{f}=31 \%$. Both the inter- and intra-bundle spacings reduce as the fibre volume fraction increases, which dominates the preform permeability more than the binder content. It is conceivable that less binder is required for preform fixation at higher fibre volume fractions, as the through-thickness pressure induced by the tool is sufficient to hold the tows in position. However, the success of this approach depends on the uniformity of the fibre distribution and the complexity of the preform geometry, as the through-thickness pressure is non-uniform and will be lower on near-vertical faces of the geometry.

Comparing the different modelling approaches, the predictions based on the 3D model show significantly smaller deviations from experimental values than predictions based on the 2D beam element model. In terms of average values, the 2D fibre model with even spacing between bundles underestimated the permeability of DCFP by $\sim 40 \%$, while the $3 D$ model overestimates the permeability by $\sim 15 \%$.

However, the trend for the effect of binder content on the permeability at different fibre volume fractions was correctly accounted for in the simulation based on the 3D model. The overestimation of experimental values by $15 \%$ can be attributed to the assumption that the 
fibres remain piecewise planar (overlooking out-of-plane fibre angles). Therefore, simulated resin flow is not hindered by fibres passing through the thickness of the preform.

\section{Conclusions}

In a series of permeability tests on DCFP preforms, the observed variability in measured values was high, which is a reflection of the variability in areal mass of the preforms. It was found that, in general, at least ten repeat tests are required to obtain convergence of the average permeability.

Experimental data also showed that the presence of powder binder has a significant influence on the permeability of DCFP preforms, when typical amounts are added for preform fixation. When the binder content was increased from $5 \mathrm{wt} \%$ to $10 \mathrm{wt} \%$, the permeability of a DCFP preform at a fibre volume fraction of $31 \%$ was reduced by $27 \%$. However, at $V_{f}=46 \%$, the reduction in preform permeability was only $15 \%$.

A permeability model was developed which accounts for local features of the 3D fibre architecture of DCFP preforms, i.e. number of tows, orientation, and through-thickness spacing, for approximation of local permeability values. Local permeability values are assigned to a 2D preform model which is used for resin injection simulations.

The results of the resin injection simulations allow global preform permeabilites to be derived. Results show that the model developed in the presented work allows to reproduce the characteristic irregular flow fronts observed in the experiments for the DCFP material. Compared to the previously developed models, the new 3D model reduced the difference between average global permeability values derived from simulations and the corresponding experimental values. The difference was reduced from $40 \%$ for the previous model to 
approximately $15 \%$ for the new approach, where the predicted values are within one standard deviation of the experimental values for each material scenario studied.

\section{Acknowledgements}

This work was done in the "ACC TECH-UNNC joint laboratory in Sustainable Composite Materials". The authors would like to acknowledge the financial supported by the Ningbo S\&T Bureau Ningbo International Collaboration Project (project code 2017D10033), and the Ningbo 3315 Innovation Team Scheme "R\&D of Lightweight High Strength SMC materials". 


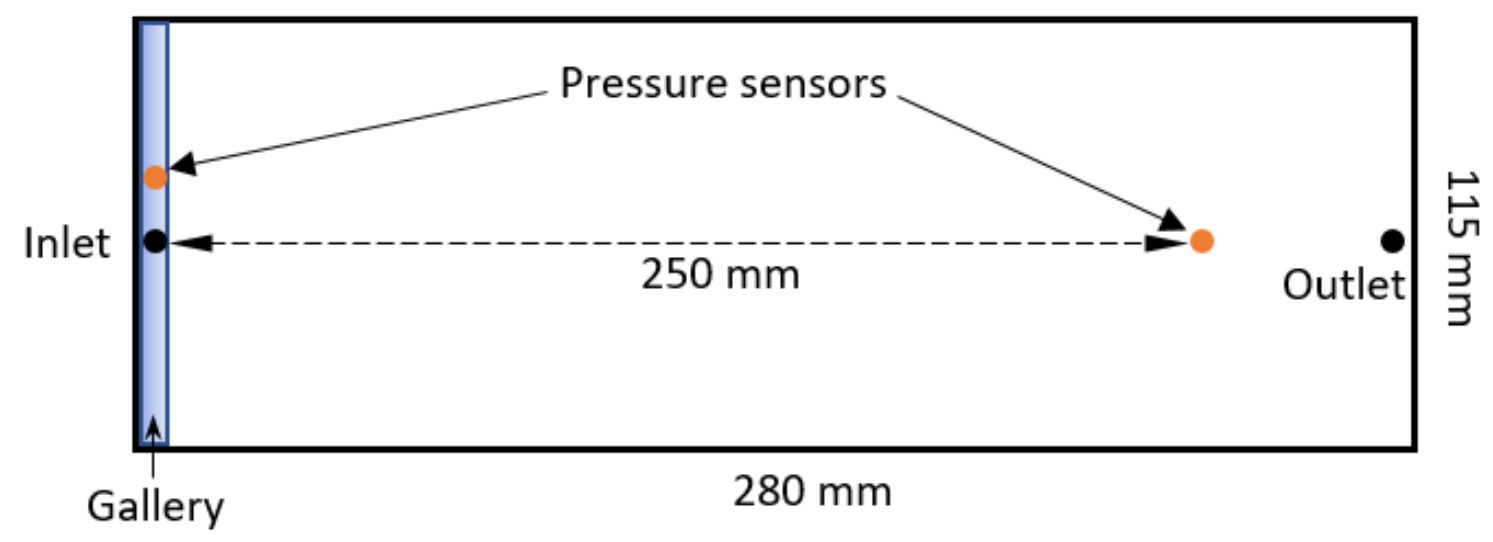

Figure 1: Geometry of uni-directional flow experiments.

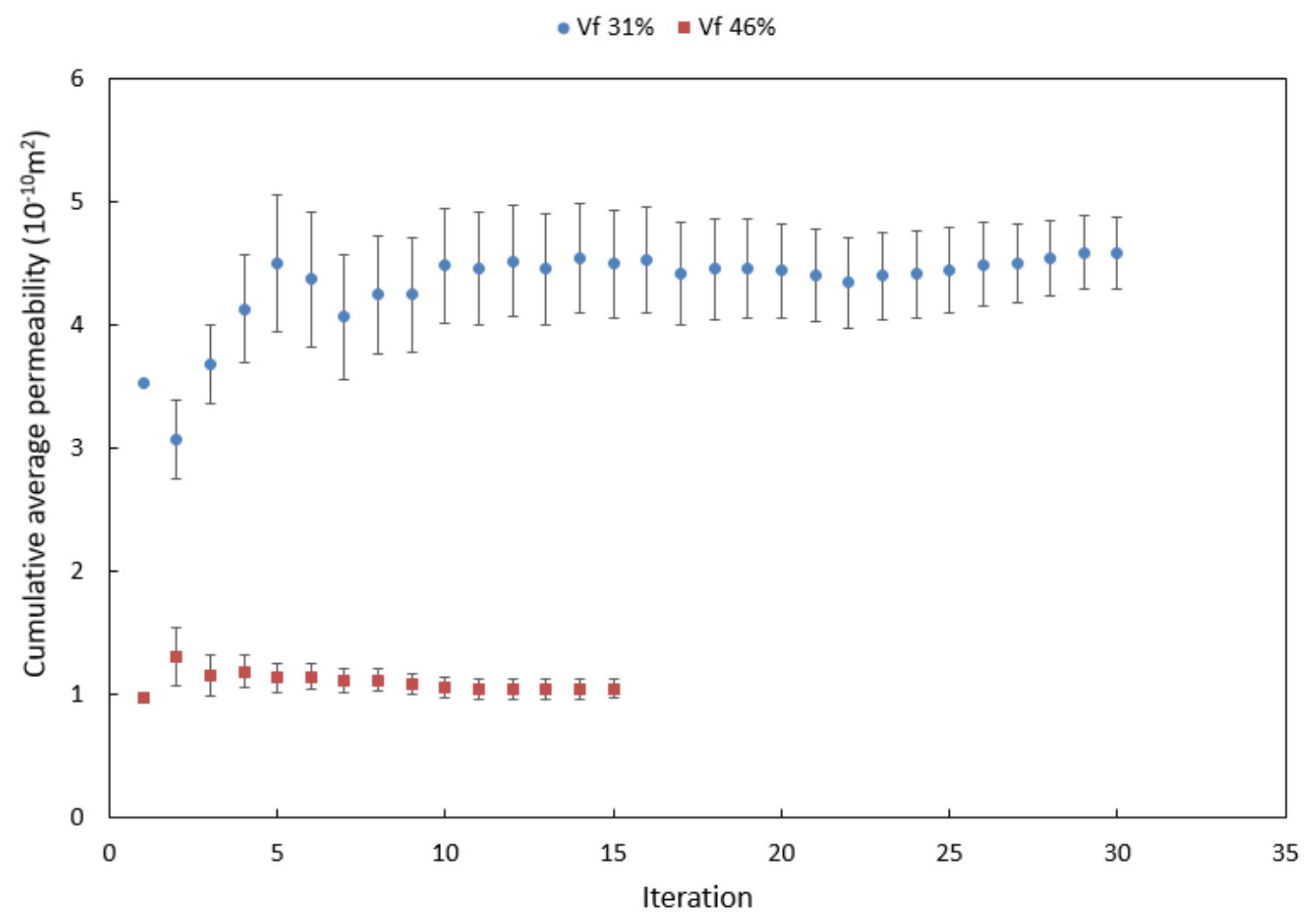

Figure 2: Cumulative average (global) permeability value as a function of number of measurements for two different DCFP preform architectures (T700 12K, $V_{f}=31 \%$ and $46 \%$, EPS620 at 10 wt\%). 


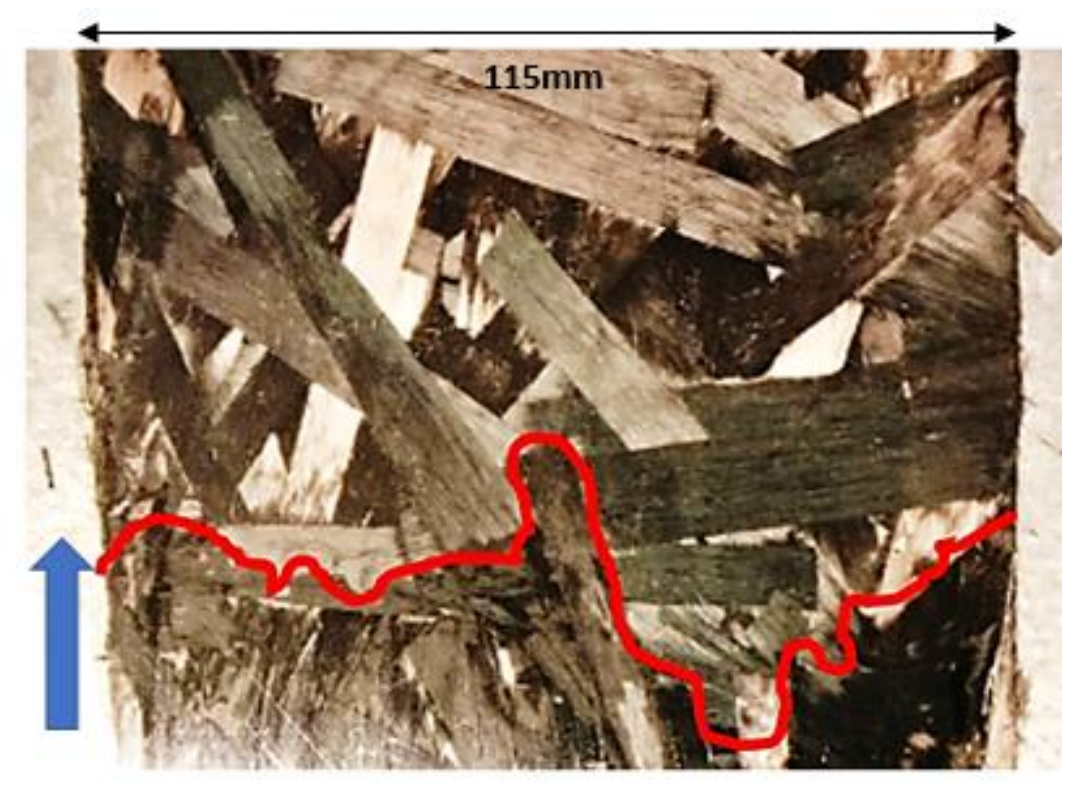

Figure 3: Typical flow front profile in a DCFP preform during an in-plane permeability test. Arrow indicates main flow direction.

- k1 घ k2

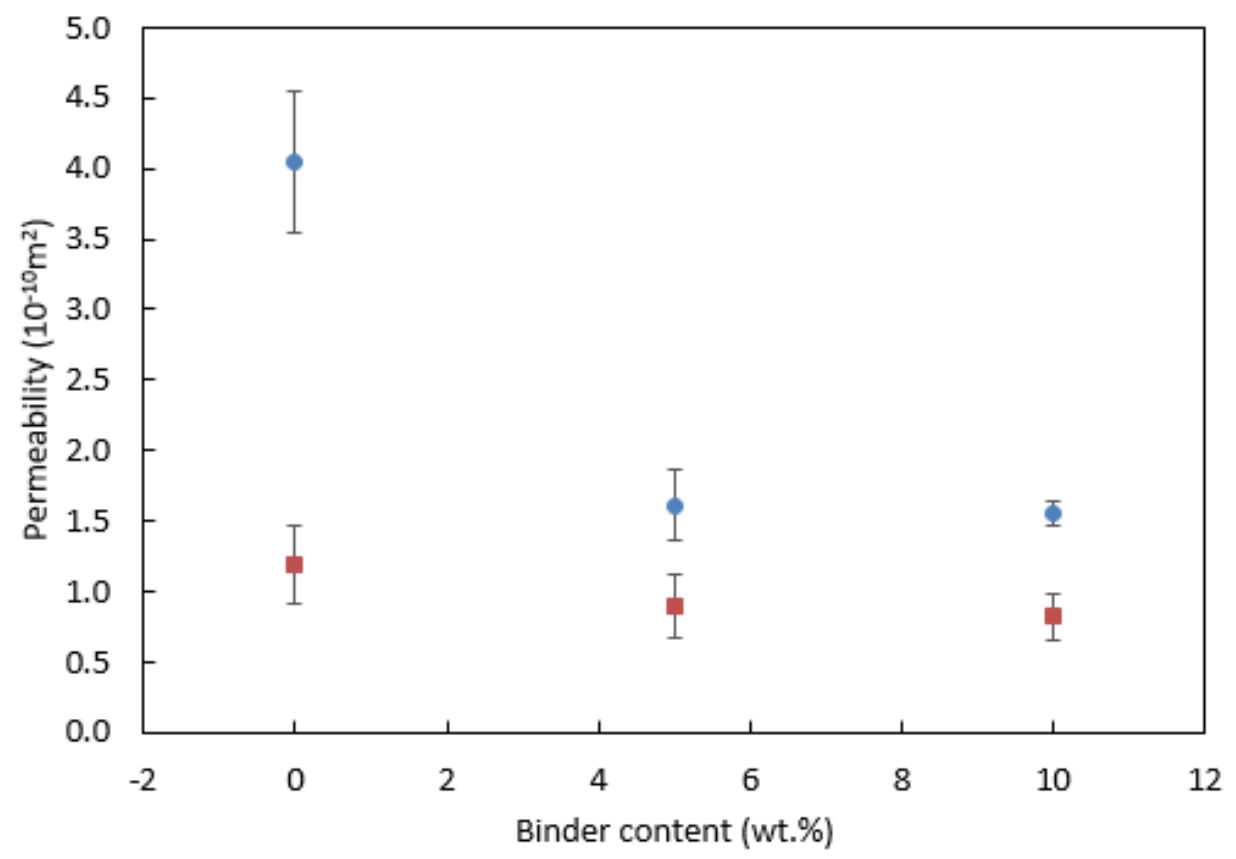

Figure 4: $k_{1}$ and $k_{2}$ values of the UD NCF preforms $\left(V_{f}=46 \%\right)$ at three levels of binder content: 0 wt\%. 5 wt $\%$ and 10 wt\%. 


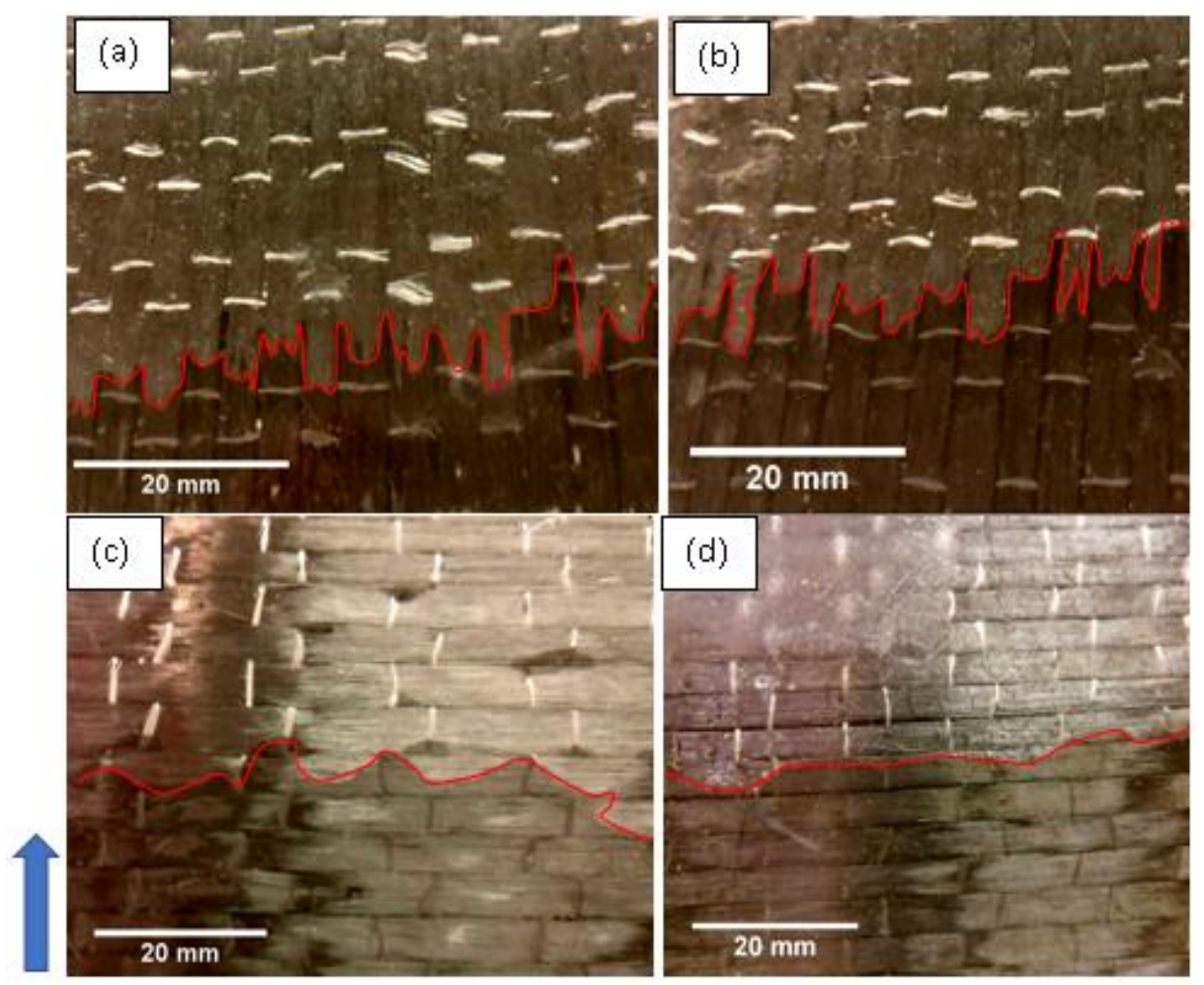

Figure 5: Profiles of flow fronts in UD-NCF preforms at different orientations and different binder levels: (a) $0 \mathrm{wt} \%, k_{1}$; (b) $10 \mathrm{wt} \%, k_{1}$; (c) $0 \mathrm{wt} \%, k_{2}$; (d) $10 \mathrm{wt} \%, k_{2}$. The blue arrow indicates the flow direction.

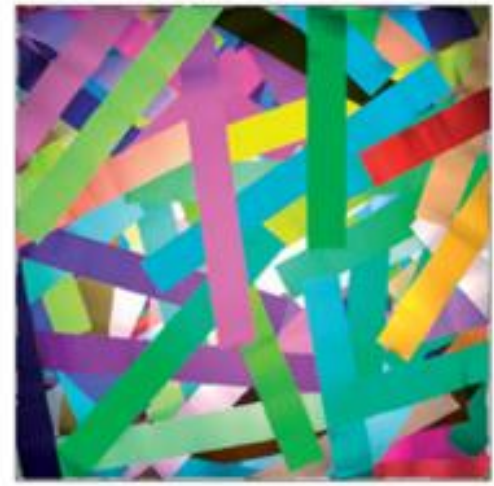

(A)

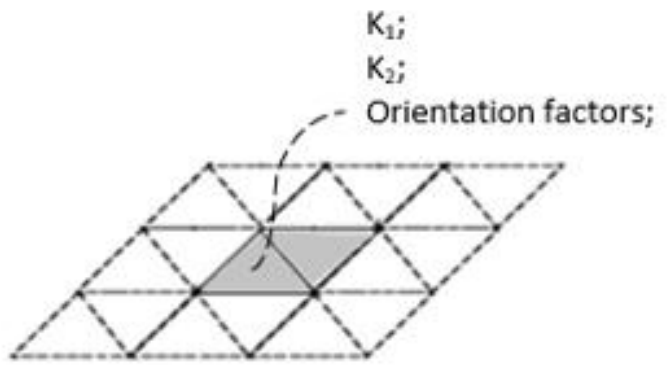

(C)

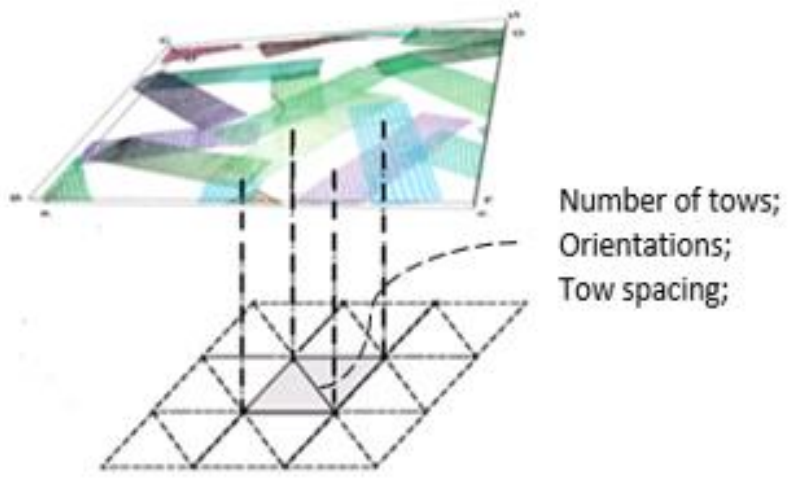

(B)

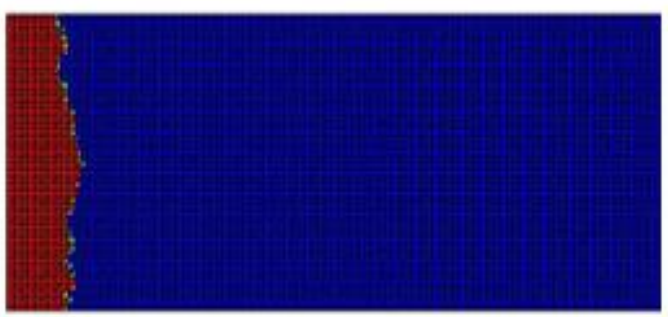

(D)

Figure 6: Schematic of permeability modelling process: (A) DCFP architecture generation [21]; (B) Fibre geometry analysis (mapping); (C) Local permeability calculation [20]; (D) Flow simulation in PAM-RTM to determine global permeability. 


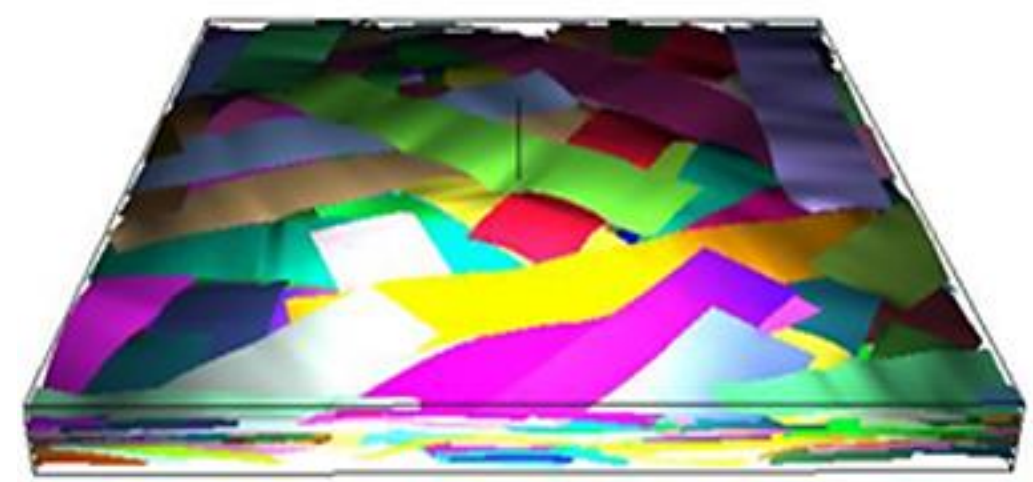

Figure 7: 3D model of DCFP preform from $45 \mathrm{~mm}$ long $12 \mathrm{~K}$ fibre bundles; dimensions: $50 \mathrm{~mm} \times 50$ $\mathrm{mm} \times 2 \mathrm{~mm}$.

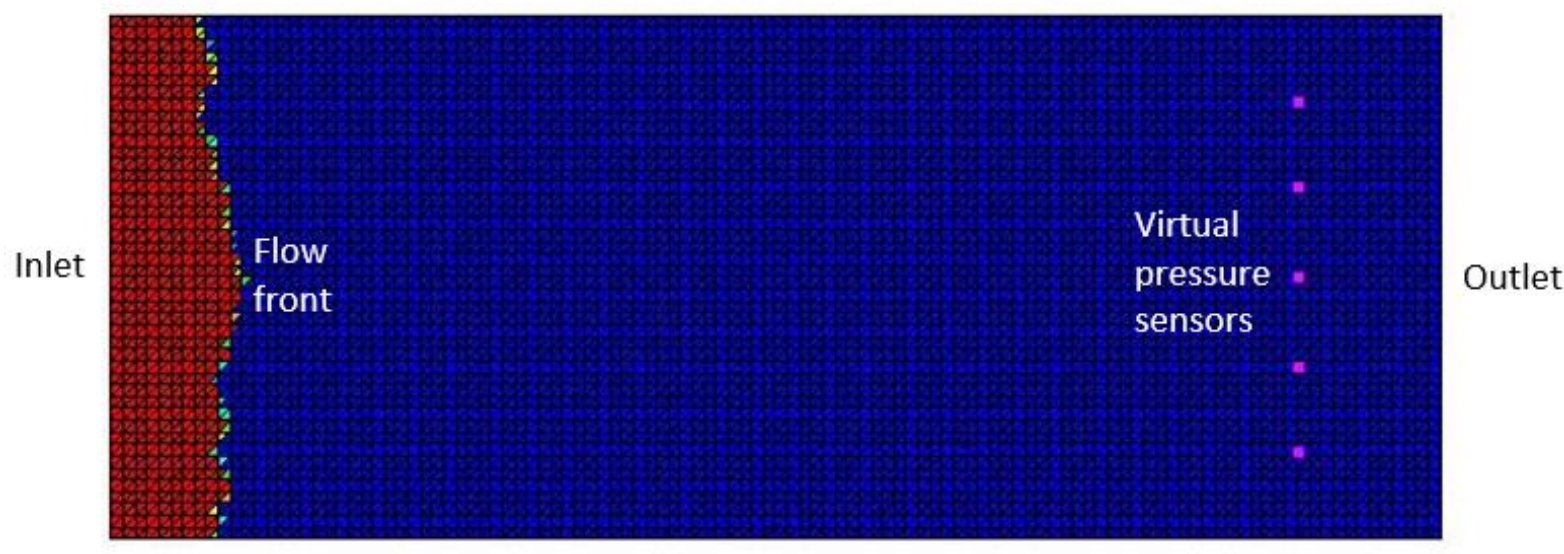

Figure 8: FE model for flow simulation in PAM-RTM $(280 \mathrm{~mm} \times 110 \mathrm{~mm})$.

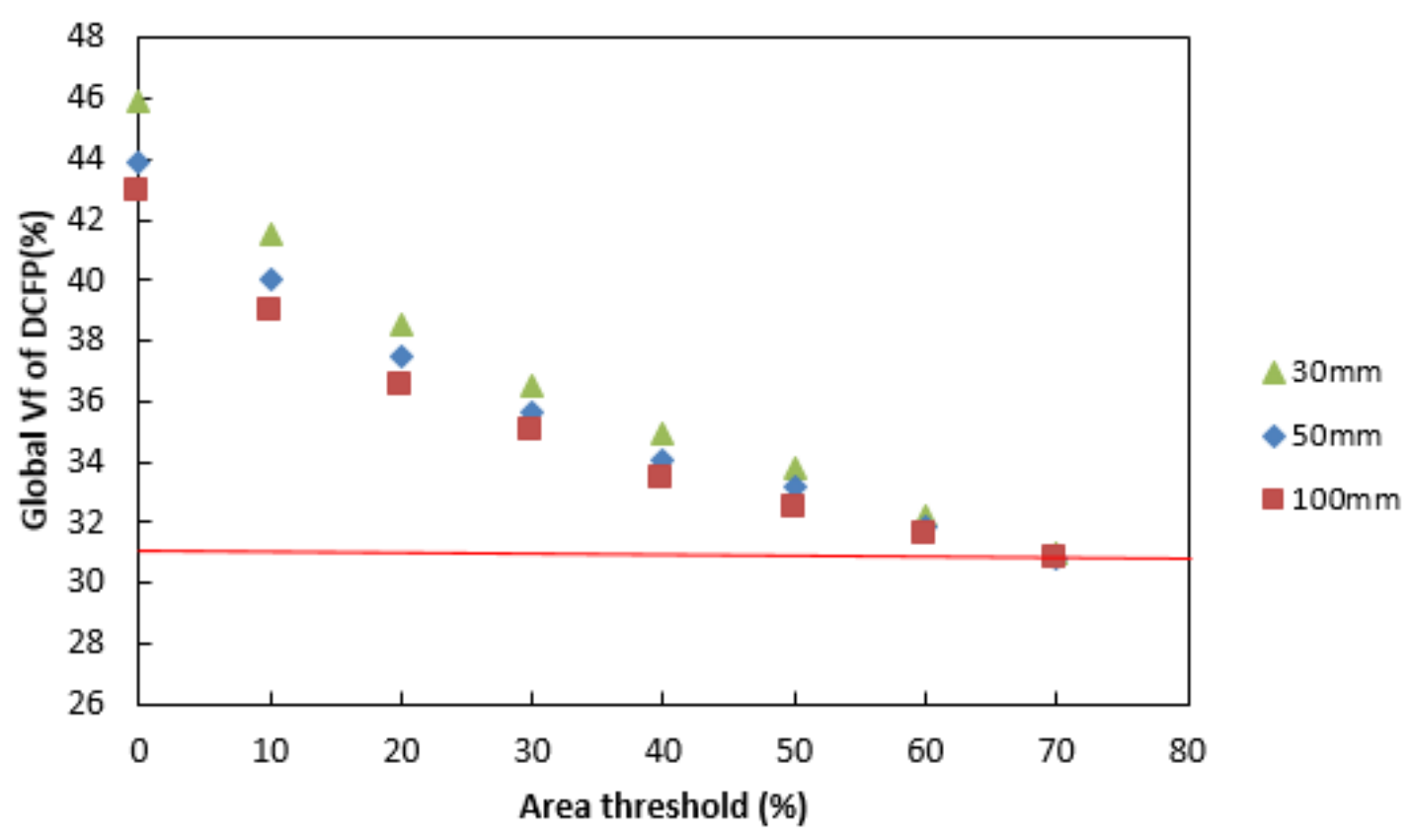

Figure 9: Global fibre volume fraction of a $280 \mathrm{~mm} \times 110 \mathrm{~mm} \times 2 \mathrm{~mm} 24 \mathrm{~K}$ fibre DCFP preform as a function of the area threshold value. The target $V_{f}$ (red line) is $31 \%$ for a range of fibre lengths (30 $\mathrm{mm}, 50 \mathrm{~mm}$ and $100 \mathrm{~mm}$ ) using different area threshold values. 


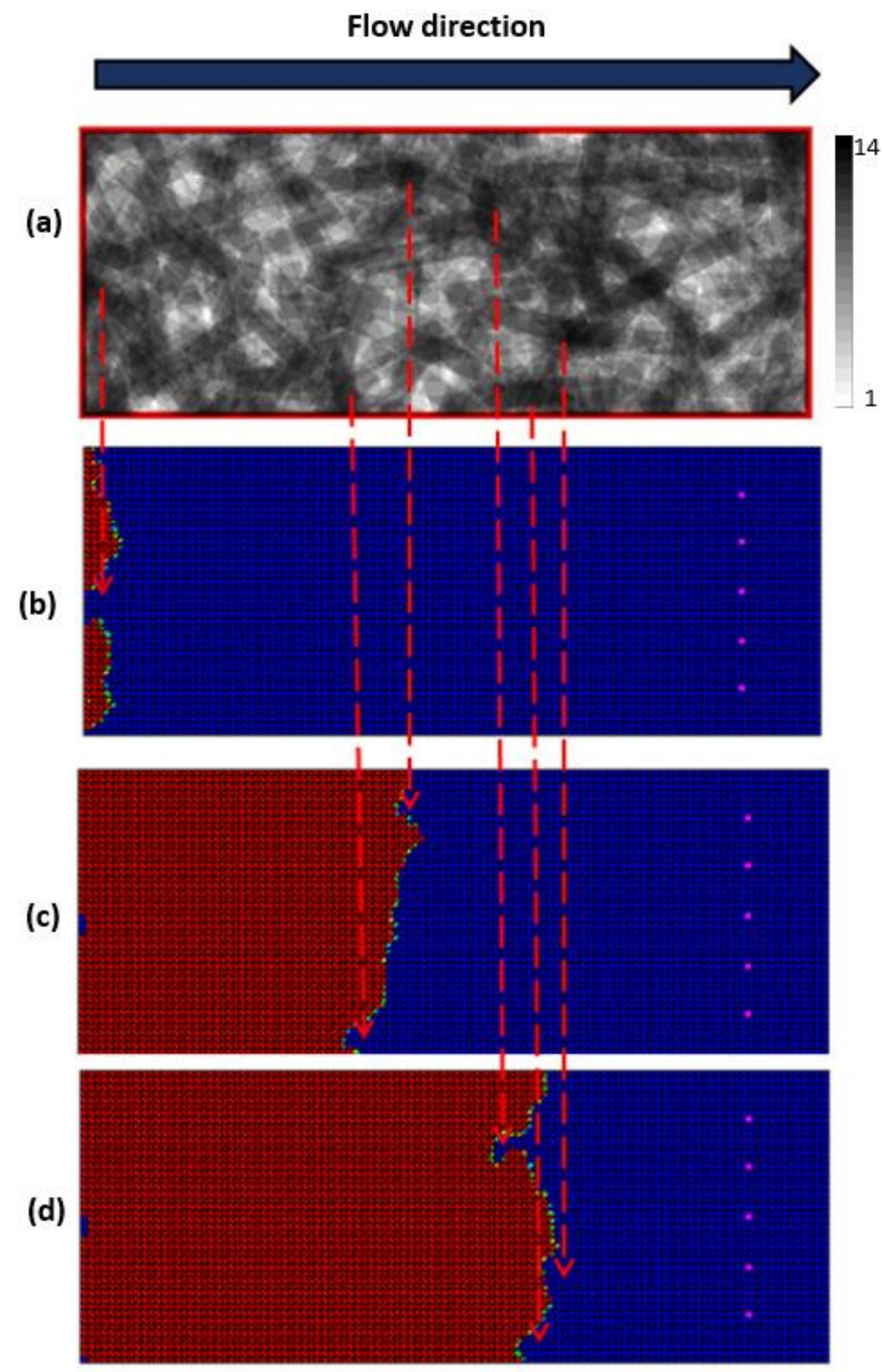

Figure 10: Fibre distribution in a DCFP model (a): scale bar indicates local number of fibre bundles; simulated fluid distributions at different stages of the injection process $(b)-(d)$; model dimensions $280 \mathrm{~mm} \times 110 \mathrm{~mm}$. 


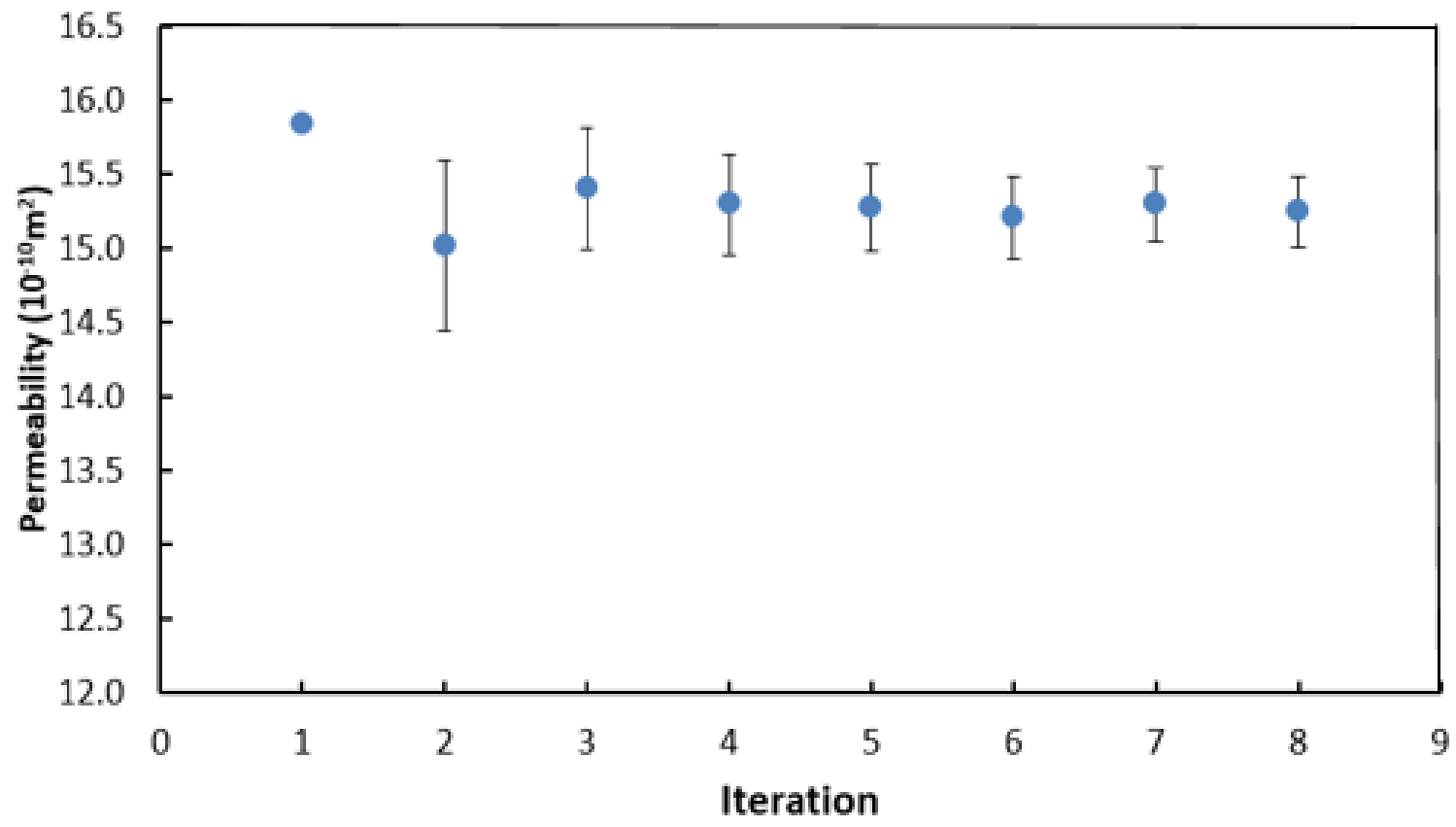

Figure 11: Cumulative average global permeability values derived from FE flow simulations in PAMRTM. 
9 Tables

Table 1: Details of preforms for permeability tests.

\begin{tabular}{|c|c|c|c|c|}
\hline Preform type & Fibre length & $\begin{array}{c}\text { Carbon } V_{f} \text { in the permeability } \\
\text { measurement mould }\end{array}$ & Binder content & Number of specimens \\
\hline \multirow{4}{*}{ DCFP } & \multirow{2}{*}{$45 \mathrm{~mm}$} & \multirow{2}{*}{$31 \%$} & $5 \mathrm{wt} \%$ & 15 \\
\hline & & & $10 \mathrm{wt} \%$ & 30 \\
\hline & \multirow{2}{*}{$45 \mathrm{~mm}$} & \multirow{2}{*}{$46 \%$} & $5 \mathrm{wt} \%$ & 15 \\
\hline & & & $10 \mathrm{wt} \%$ & 15 \\
\hline \multirow{3}{*}{ UD-NCF } & \multirow{3}{*}{ - } & \multirow{3}{*}{$46 \%$} & $0 \mathrm{wt} \%$ & 15 \\
\hline & & & $5 \mathrm{wt} \%$ & 15 \\
\hline & & & $10 \mathrm{wt} \%$ & 15 \\
\hline
\end{tabular}

Table 2: Average permeability values for UD NCF at different binder levels.

\begin{tabular}{|c|c|c|c|}
\hline \multirow{2}{*}{ Permeability } & \multicolumn{3}{|c|}{ Binder content } \\
\cline { 2 - 4 } & $\mathbf{0} \mathbf{w t} \%$ & $\mathbf{5} \mathbf{w t} \%$ & $\mathbf{1 0} \mathbf{w t} \%$ \\
\hline$k_{1}\left(\mathbf{1 0}^{-10} \mathbf{m}^{\mathbf{2}}\right)$ & 4.04 & $1.61(-60.1 \%)$ & $1.55(-3.7 \%)$ \\
\hline$k_{2}\left(\mathbf{1 0}^{-10} \mathbf{m}^{2}\right)$ & 1.19 & $0.90(-24.4 \%)$ & $0.82(-8.9 \%)$ \\
\hline
\end{tabular}


Table 3: Fibre architectures generated in this work and their meshing information.

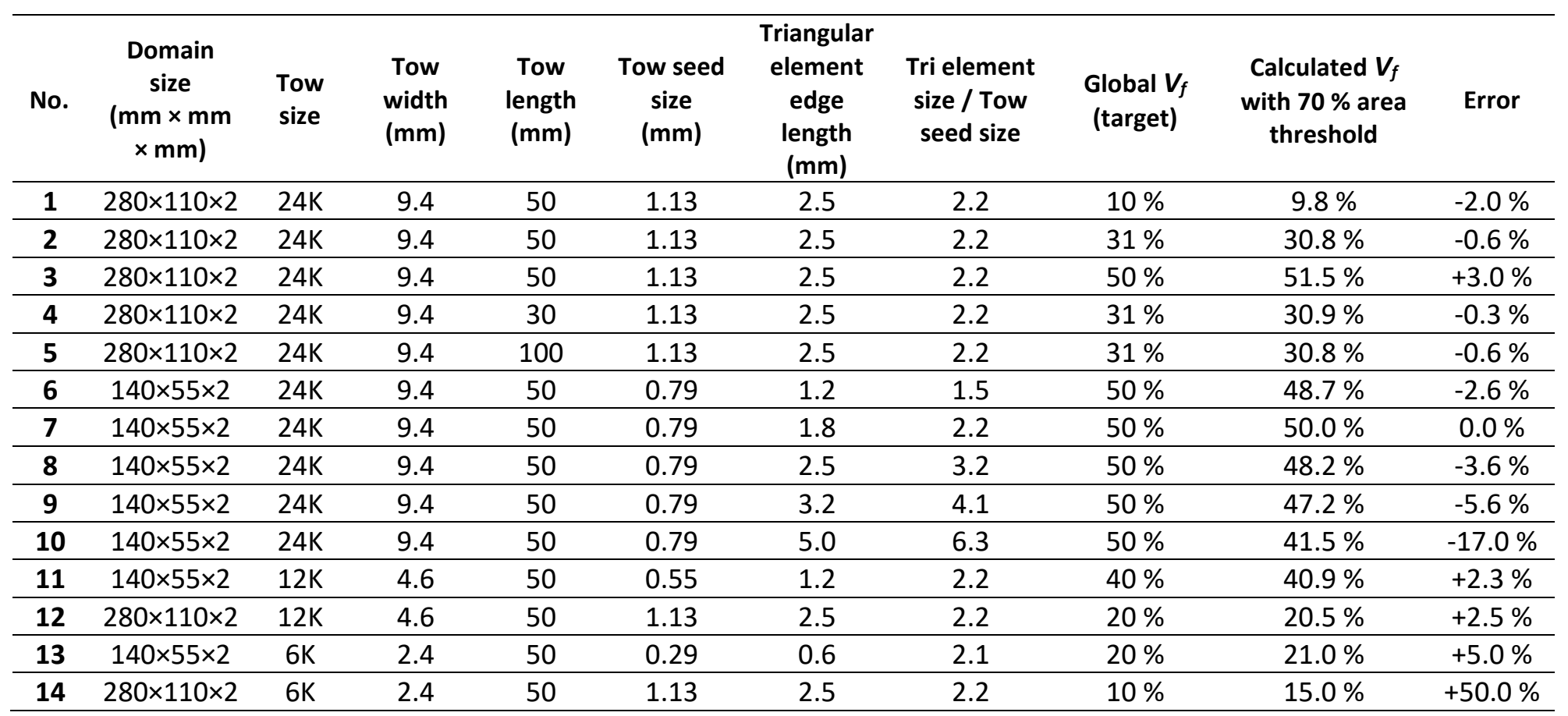

Table 4: Parameters used for calculation of local permeabilities.

\begin{tabular}{|c|c|c|c|c|}
\hline \multirow{2}{*}{$\begin{array}{c}\text { Fibre density } \\
\left(\mathbf{k g} / \mathbf{m}^{\mathbf{3}}\right)\end{array}$} & $\begin{array}{c}\text { Fibre diameter } \\
(\mathbf{m m})\end{array}$ & \multicolumn{3}{|c|}{ Quadratic packing } \\
\cline { 3 - 5 } & 0.007 & 1.78 & $\boldsymbol{c}_{\mathbf{2}}$ & $\boldsymbol{V}_{\text {fmax }}$ \\
\hline 1800 & 0.40 & $78.5 \%$ \\
\hline
\end{tabular}


Table 5: Computing time at different triangular element sizes for the $24 \mathrm{~K}$ fibre (9.4 $\mathrm{mm}$ wide) architectures (Architectures 6 to 10 in Table 3 ).

\begin{tabular}{cccccc}
\hline Grid size $(\mathrm{mm})$ & 1.2 & 1.8 & 2.5 & 3.2 & 5.0 \\
\hline $\begin{array}{c}\text { Fibre tow width to } \\
\text { element size ratio }\end{array}$ & 7.8 & 5.2 & 3.8 & 2.9 & 1.9 \\
\hline $\begin{array}{c}\text { Computing time } \\
\text { (s) }\end{array}$ & 267 & 55 & 28 & 17 & 7
\end{tabular}

Note: The specification for the computer used in this work is: CPU Core i3-4130, 3.4GHz and 32GB RAM.

Table 6: Comparison of permeability values of the DCFP $(12 \mathrm{~K}, 45 \mathrm{~mm})$ at different $V_{f}$ and binder content; experimental measurement, simulation based on 2D model and simulation based on 3D model.

\begin{tabular}{|c|c|c|c|c|c|c|}
\hline $\begin{array}{c}\text { Permeability } \\
\left(\mathbf{1 0}^{-\mathbf{1 0}} \mathbf{~}^{\mathbf{2}}\right)\end{array}$ & Experimental & 3D model & 2D model & Experimental & 3D model & 2D model \\
\hline & \multicolumn{3}{|c|}{5 wt\% binder } & & \multicolumn{3}{c|}{10 wt\% binder } \\
\hline$V_{f}$ & $6.32 \pm 1.92$ & $7.43 \pm 0.88$ & $3.93 \pm 0.22$ & $4.59 \pm 1.13$ & $5.94 \pm 0.67$ & $2.94 \pm 0.19$ \\
\hline $31 \%$ & $1.34 \pm 0.45$ & $1.54 \pm 0.38$ & $0.83 \pm 0.13$ & $1.13 \pm 0.33$ & $1.28 \pm 0.29$ & $0.75 \pm 0.12$ \\
\hline $46 \%$ & &
\end{tabular}




\section{References}

1. Harper, L.T., Turner, T.A., Warrior, N.A., Dahl, J.S., and Rudd, C.D., Characterisation of random carbon fibre composites from a directed fibre preforming process: Analysis of microstructural parameters. Composites Part A: Applied Science and Manufacturing, 2006. 37(11): p. 2136-2147.

2. Chavka, N.G. and Dahl, J.S., P4: Glass fiber preforming technology for automotive applications, in 44th International SAMPE Symposium. 1999: Long Beach, CA, USA, 23-27 May 1999.

3. DeVries, J.E., Chavka, N.G., and Dahl, J.S. Recent advances in glass fiber preforming: Implementation of the Ford Programmable Preform Process (F3P). in International Conference for Manufacturing of Advanced Composites. Belfast, 27-28 September 2001.

4. Turner, T.A., Harper, L.T., Warrior, N.A., and Rudd, C.D., Low - cost carbon - fibre - based automotive body panel systems: a performance and manufacturing cost comparison. Proceedings of the Institution of Mechanical Engineers, Part D: Journal of Automobile Engineering, 2008. 222(1): p. 53-63.

5. Endruweit, A., Harper, L.T., Turner, T.A., Warrior, N.A., and Long, A.C., Random Discontinuous Carbon Fiber Preforms: Experimental Permeability Characterization and Local Modeling, . Polymer Composites, 2010. 31(4): p. 569-580.

6. Sharma, S. and Siginer, D.A., Permeability Measurement Methods in Porous Media of Fiber Reinforced Composites. Appl Mech Rev 2010; 63: 020802-1-020802-19.

7. Carlone, P. and Palazzo, G.S., Unsaturated and Saturated Flow Front Tracking in Liquid Composite Molding Processes using Dielectric Sensors. Applied Composite Materials, 2015. 22(5): p. 543-557.

8. Lawrence, J.M., Neacsu, V., and Advani, S.G., Modeling the impact of capillary pressure and air entrapment on fiber tow saturation during resin infusion in LCM. Composites Part A: Applied Science and Manufacturing, 2009. 40(8): p. 1053-1064.

9. Carlone, P., Rubino, F., Paradiso, V., and Tucci, F., Multi-scale modeling and online monitoring of resin flow through dual-scale textiles in liquid composite molding processes. The International Journal of Advanced Manufacturing Technology, 2018. 96(5): p. 2215-2230.

10. Amico, S. and Lekakou, C., An experimental study of the permeability and capillary pressure in resin-transfer moulding. Composites Science and Technology, 2001. 61: p. 1945-1959.

11. Foley, M.E. and Gillespie, J.W., Modeling the Effect of Fiber Diameter and Fiber Bundle Count on Tow Impregnation during Liquid Molding Processes. Journal of Composite Materials, 2005. 39(12): p. 1045-1065.

12. Park, C.H., Lebel, A., Saouab, A., Bréard, J., and Lee, W.I., Modeling and simulation of voids and saturation in liquid composite molding processes. Composites Part A: Applied Science and Manufacturing, 2011. 42(6): p. 658-668.

13. Amico, S. and Lekakou, C., Flow Through a Two-Scale Porosity, Oriented Fibre Porous Medium. Transport in Porous Media, 2004. 54(1): p. 35-53.

14. Xiao, Z., Advancements in Discontinuous Carbon Fibre Composite Technologies for High Volume Manufacturing Processes. 2018, University of Nottingham. p. 189.

15. Khoun, L., Maillard, D., and Bureau, M.N. Effect of process variables on the performance of glass fibre reinforced composites made by high pressure resin transfer moulding. in Proceedings of the 12th Annual Automotive Composites Conference and Exhibition (ACCE 2012). Troy, MI, USA, 1113 September 2012.

16. Rosenberg, P., Chaudhan, R., Albrecht, P., Karcher, M., and Henning, F., Effects of process parameters on cavity pressure and component performance in high-pressure RTM process variants, in SPE ACCE 2014. Novi, MI, USA, 9-11 September 2014.

17. Bodaghi, M., Cristóvão, C., Gomes, R., and Correia, N.C., Experimental characterization of voids in high fibre volume fraction composites processed by high injection pressure RTM. Composites Part A: Applied Science and Manufacturing, 2016. 82: p. 88-99.

18. Rohatgi, V. and Lee, L.J., Moldability of tackified fiber preforms in liquid composite molding. Journal of Composite Materials, 1997. 31(7): p. 720-744. 
19. Brody, J.C. and Gillespie, J.W., The Effects of a Thermoplastic Polyester Preform Binder on Vinyl Ester Resin. Journal of Thermoplastic Composite Materials, 2005. 18(3): p. 157-179.

20. Endruweit, A., Harper, L.T., Turner, T.A., Warrior, N.A., and Long, A.C., Random discontinuous carbon fibre preforms: Permeability modelling and resin injection simulation. Composites Part A: Applied Science and Manufacturing, 2008. 39(10): p. 1660-1669.

21. Harper, L., Qian, C., Luchoo, R., and Warrior, N., 3D geometric modelling of discontinuous fibre composites using a force-directed algorithm. Journal of Composite Materials, 2017. 51(17): p. 2389-2406.

22. Parnas, R.S. and Salem, A.J., A comparison of the unidirectional and radial in-plane flow of fluids through woven composite reinforcements. Polymer Composites, 1993. 14(5): p. 383-394.

23. Wong, C.C., Modelling the effects of textile preform architecture on permeability. PhD Thesis, University of Nottingham, 2006.

24. Gebart, B.R., Permeability of Unidirectional Reinforcements for RTM. Journal of Composite Materials, 1992. 26(8): p. 1100-1133.

25. Ni, J., Zhao, Y., Lee, L.J., and Nakamura, S., Analysis of two-regional flow in liquid composite molding. Polymer Composites, 1997. 18(2): p. 254-269.

26. TORAYCA. Technical Data Sheet No. CFA-005 28/06/2017], https://www.toraycma.com/file_viewer.php?id=5116 (accessed 19 January 2020). TORAYCA. Technical Data Sheet No. CFA-005 28/06/2017], https://www.toraycma.com/file_viewer.php?id=5116 (accessed 19 January 2020). 